\title{
INDEKS PENGARANG
}

$\begin{array}{llll}\text { Adityo } & 550 & \text { Muhammad Ragil Kurniawan } & 491 \\ \text { Ainur Rofieq } & 542 & \text { Noventy Prasetyaningsih } & 507 \\ \text { Amalia Ayu Wardhany } & 550 & \text { Prasis Indahwati } & 518 \\ \text { Buaddin Hasan } & 449 & \text { Robertus Adi Sarjono Owon } & 528 \\ \text { Dyah Worowirastri Ekowati } & 459 & \text { Roimil Latifa } & 542 \\ \text { Erna Yayuk } & 459 & \text { Rr. Eko Susetyarini } & 542 \\ \text { Hainuatus Zahroh } & 469 & \text { Sri Wahyuni } & 542 \\ \text { Maria Fransiska Lestari } & & \text { Teguh Hadi Saputro } & 550 \\ \text { Budi Utami } & 483 & & \end{array}$




\section{INDEKS SUBJEK}

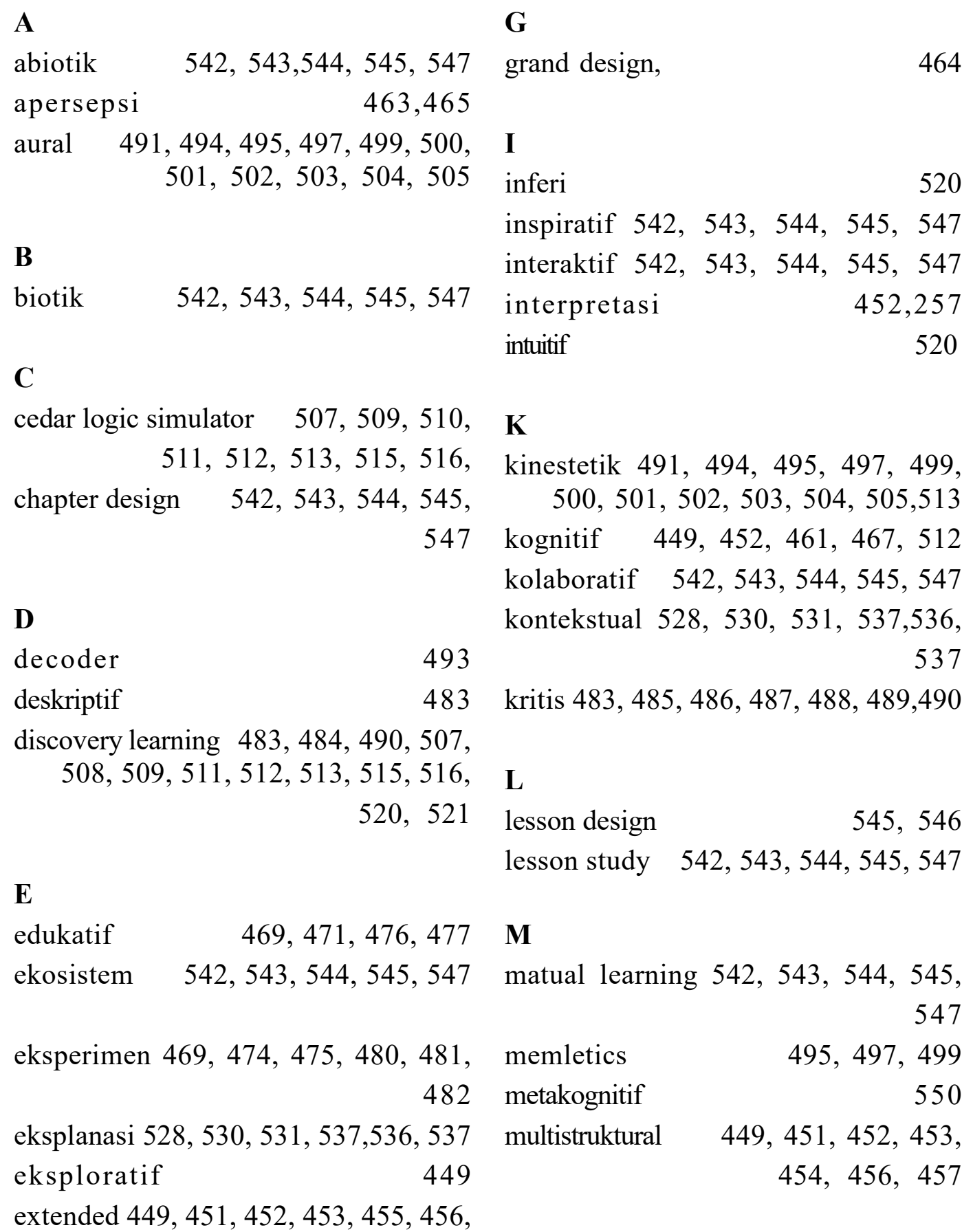




\section{$\mathbf{N}$}

nau noan 528, 530, 531, 537, 536, 537

$\mathbf{P}$

pameran berjalan $518,519,520,522$, $523,525,526,527$

pete peron 528, 530, 531, 537,536, 537

physikal 491, 494, 495, 497, 499, 500, 501, 502, 503, 504, 505

phytagoras 454, 455, 456 prototipe $528,529,531,536,537,540$

$\mathbf{R}$

refleksi 459, 461, 462, 463, 465, 466 research and development 469, 470, $473,528,530,531,537,536,537$

$\mathbf{S}$

saka seng 528, 530, 531, 537,536, 537

scaffolding $\quad 526$

sintesis $\quad 460$

T

tu tuak 528, 530, 531,537,536,537

two stay two stray $\quad 542,543,544$,

545,547

V

verbal 491, 494, 495, 497, 499, 500, $501,502,503,504,505$

visual 491, 494, 495, 497, 499, 500, $501,502,503,504,505$

W

wisdom 528, 530, 531, 537,536, 537 


\section{Petunjuk Penulisan Artikel JINoP (Jurnal Inovasi Pembelajaran)}

1. Artikel yang ditulis berdasarkan hasil penelitian pembelajaran di semua bidang studi dan jenjang pendidikan. Naskah diketik dengan program Microsoft Word dan huruf Times New Roman dengan ukuran font 12, dengan satu spasi, dicetak pada kertas A4 dengan jumlah halaman 10-15. Naskah diserahkan dalam bentuk print-out sebanyak 1 eksemplar beserta soft-copy (file). File dapat dikirim ke e-mail: jinopfkip@gmail.com dan jinopfkip@umm.ac.id

2. Nama penulis dicantumkan tanpa gelar akademik ditempatkan di bawah judul artikel, disertai lembaga asal dan alamat korespondensi (e-mail ). Dalam hal naskah ditulis oleh tim, penyunting hanya berhubungan dengan penulis utama atau penulis yang namanya tercantum pada urutan pertama.

3. Artikel ditulis dalam bahasa Indonesia atau Inggris secara benar dengan mengikuti ketentuan dalam petunjuk penulisan artikel ilmiah. Judul artikel ditulis dengan huruf kapital di tengah-tengah dengan ukuran 14 font. Adapun subjudul ditulis mulai margin kiri lurus tanpa menggunakan penomoran. Sub-subjudul dicetak tebal, judul artikel dalam bahasa Indonesia tidak lebih dari 14 kata, sedangkan judul dalam bahasa Inggris tidak lebih dari 12 kata.

4. Artikel ditulis dengan sistematika: judul, nama penulis, lembaga asal, alamat korespondensi e-mail; abstrak (ditulis dalam dua bahasa Indonesia dan Inggris sedangkan untuk artikel bahasa inggris maka abstraknya hanya bahasa inggris saja, panjang masing-masing abstrak tidak lebih dari 200 kata); berisi tujuan, metode, hasil penelitian dan kesimpulan utama); kata kunci (3-5 kata); pendahuluan (berisi latar belakang, konteks penelitian, hasil kajian pustaka, dan tujuan penelitian, yang semuanya dipaparkan secara terintegrasi dalam bentuk paragraf-paragraf, dengan persentase $15-20 \%$ dari keseluruhan artikel); metode (berisi paparan dalam bentuk paragraf tentang rancangan penelitian, sumber data, teknik pengumpulan data, dan analisis data yang secara nyata dilakukan peneliti, dengan persentase $10-15 \%$ dari keseluruhan artikel); hasil dan pembahasan (hasil penelitian berisi paparan hasil analisis yang berkaitan dengan pertanyaan penelitian, sedangkan pembahasan berisi pemaknaan hasil dan perbandingan dengan teori dan/atau hasil penelitian sejenis, dengan persentase $40-60 \%$ dari keseluruhan artikel), Hasil penelitian dapat dilengkapi dengan tabel, grafik (gambar), dan/atau bagan. Kemungkinan tindak lanjut kegiatan dapat juga disampaikan pada bagian ini; kesimpulan (berisi temuan penelitian yang berupa jawaban atas pertanyaan penelitian atau berupa intisari hasil pembahasan, yang disajikan dalam bentuk paragraf), saran dapat disampaikan pada bagian ini; daftar pustaka (memuat sumber-sumber yang dirujuk dan semua sumber yang dirujuk harus tercantum dalam daftar pustaka)

5. Mohon memberikan $\underline{\text { No. HP }}$ untuk koresponden atau kontak person. 
6. Sumber rujukan sedapat mungkin berupa pustaka terbitan mutakhir dan diutamakan rujukan yang digunakan adalah sumber-sumber primer berupa artikelartikel penelitian dalam jurnal/majalah ilmiah atau laporan penelitian (skripsi, tesis, disertasi).

7. Perujukan/pengutipan menggunakan teknik rujukan berkurung dan untuk kutipan langsung disertai tahun, tempat asal kutipan dan halaman , misalnya: (Miller, 2011: 100)

8. Daftar pustaka disusun secara alfabetis dan kronologis dengan urutan seperti contoh berikut.

\section{Rujukan Buku:}

Noddings, N. 1993. Educating for Intelligent Belief or Unbelief. New York: Teacher College Press.

\section{Rujukan Artikel dalam Buku Kumpulan Artikel}

Margono. 2008. Manajemen Jurnal Ilmiah. Dalam M.G Waseso \& A. Saukah (Eds.), Menerbitkan Jurnal Ilmiah (hlm. 46-50). Malang: UMM Press.

\section{Rujukan Berupa Buku yang Ada Editornya}

Rusli, Marah. 2005. Sosiologi Pendidikan: Kajian Berdasarkan Teori Integritas Mikro-Makro (Arnaldi. S Ed.) Malang: UMM Press.

\section{Rujukan dari Buku yang Berasal dari Perpustakaan Elektronik}

Dealey, C. 1998. The Care of Wounds: A Guide for Nurses. Oxford: Blackwell Science. Dari NetLibrary, (Online), (http://netlibrary.com), diakses 26 Agustus 2012.

\section{Rujukan dari Artikel dalam Internet Berbasis Jurnal Tercetak}

Mappiare-AT, A., Ibrahim, A.S. \& Sudjiono. 2009. Budaya Komunikasi RemajaPelajar di Tiga Kota Metropolitan Pantai Indonesia. Jurnal Ilmu Pendidikan, (Online), 16 (1): 12-21, (http://www.umm.ac.id) diakses 28 Oktober 2009

\section{Rujukan dari Artikel dalam Jurnal dari CD-ROM}

Krashen, S., Long, M. \& Scarcella, R. 2007. Age, Rate and Evantual Attainment in Second Language Acquisition. TESOL Quarterly, 13: 543-567 (CD-ROM: TESOL Quarterly-Digital, 2007).

\section{Rujukan Artikel dalam Jurnal atau Majalah:}

Wentzel, K. R. 1997. Student Motivation in Middle School: The Role of Perceived Pedagogical Caring. Journal of Educational Psychology, 89 (3), 411-419. 


\section{Buku Terjemahan:}

Habermas , Jurgen. 2007. Teori Tindakan Komunikatif II: Kritik atas Rasio Fungsionaris. Terjemahan oleh Nurhadi. Yogyakarta: Kreasi Wacana.

\section{Rujukan dari Dokumen Resmi Pemerintah yang diterbitkan oleh Lembaga tersebut}

Undang-Undang Sistem Pendidikan Nasional (UURI No. 20 Tahun 2003 dan Peraturan Pelaksanaannya. 2003. Jakarta: Departemen Pendidikan Nasional.

\section{Rujukan dari Koran tanpa penulis}

Jawa Pos, 27 Mei 2015. “Komitmen Mendikbud Segarkan Pramuka”. Halaman 3.

\section{Rujukan dari Internet:}

Winingsih, H. Lucia, dkk. 2007. Peningkatan Mutu, Relevansi dan Daya Saing Pendidikan. Jakarta: Pusat Dokumentasi dan Informasi Ilmiah-Lembaga Ilmu Pengetahuan Indonesia PDII-LIPI, diakses 2 Desember 2014 on-line www. Pdii.lipi.go.id/katalog/index. php/search catalog /byld/257453.

\section{Rujukan Berupa Skripsi, Tesis, atau Disertasi.}

Mulyana, Yoyo. 2000. Keefektifan Model Mengajar Respons Pembaca dalam Pengajaran Pengkajian Puisi. Disertasi tidak Diterbitkan. Bandung: Fakultas Fakultas Bahasa dan Seni Universitas Pendidikan Indonesia.

Musaffak. 2013. Peningkatan Kemampuan Membaca Kritis dengan Menggunakan Metode Mind Mapping. Tesis tidak Diterbitkan. Malang: PPs UM.

8. Segala sesuatu yang menyangkut perizinan pengutipan atau penggunaan software komputer untuk pembuatan naskah atau ihwal lain yang terkait dengan HaKI yang dilakukan oleh penulis artikel, berikut konsekuensi hukum yang mungkin timbul karenanya, menjadi tanggung jawab penuh penulis artikel. 


\title{
JUDUL DITULIS DENGAN \\ FONT TIMES NEW ROMAN 14 CETAK TEBAL (MAKSIMUM 14 KATA)
}

\section{Penulis1 1), Penulis2 $^{2)}$ dst. [Font Times New Roman 12, tanpa gelar dan Tidak Boleh Disingkat]}

${ }^{1}$ Nama Institusi (penulis 1, time new roman 11) email: penulis_1@abc.ac.id (time new roman 11) ${ }^{2}$ Nama Institusi (penulis 1 , time new roman 11) email: penulis_2@abc.ac.id (time new roman 11)

\begin{abstract}
ABSTRAK [Times New Roman 10, bahasa Indonesia]
Abstrak ditulis dalam bahasa indonesia berisikan tujuan penelitian, metode/pendekatan penelitian dan hasil penelitian. Abstrak ditulis dalam satu alenia, tidak lebih dari 200 kata. (Times New Roman 10, spasi tunggal).

Kata kunci: 3-5 kata kunci dipisahkan dengan tanda koma. [Font Times New Roman 10, spasi tunggal].
\end{abstract}

\begin{abstract}
Times New Roman 10, bahasa Inggris]
Abstrak ditulis dalam bahasa Inggris yang berisikan tujuan penelitian, metode/pendekatan penelitian dan hasil penelitian. Abstrak ditulis dalam satu alenia, tidak lebih dari 200 kata. (Times New Roman 10, spasi tunggal).
\end{abstract}

Keywords: 3-5 kata kunci dipisahkan dengan tanda koma. [Font Times New Roman 10, spasi tunggal]

\section{PENDAHULUAN [Times New Roman 12 bold]}

Pendahuluan (berisi latar belakang,konteks penelitian, hasil kajian pustaka, dan tujuan penelitian, yang semuanya dipaparkan secara terintegrasi dalam bentuk paragrafparagraf, dengan persentase $15-20 \%$ dari keseluruhan artikel) Tinjauan pustaka yang relevan dan pengembangan hipotesis (jika ada) dimasukkan dalam bagian ini. [Times New Roman, 12, normal].

\section{METODE}

Metode menjelaskan paparan dalam bentuk paragraf tentang rancangan penelitian, sumber data, teknik pengumpulan data, dan analisis data yang secara nyata dilakukan peneliti, dengan persentase 10-15\% [Times New Roman, 12, normal]. 


\section{HASIL DAN PEMBAHASAN}

Hasil penelitian berisi paparan hasil analisis yang berkaitan dengan pertanyaan penelitian, sedangkan pembahasan berisi pemaknaan hasil dan perbandingan dengan teori dan/atau hasil penelitian sejenis, dengan persentase 40-60\% dari keseluruhan artikel); Hasil penelitian dapat dilengkapi dengan tabel, grafik (gambar), dan/atau bagan. Kemungkinan tindak lanjut kegiatan dapat juga disampaikan pada bagian ini [Times New Roman, 12, normal].

\section{Tabel 1. Nama Tabel (contoh table 1)}

\begin{tabular}{lccc}
\hline & & \multicolumn{2}{c}{$95 \% \mathrm{CI}$} \\
\cline { 3 - 4 } Condition & $M(S D)$ & $\mathrm{LL}$ & $\mathrm{UL}$ \\
\hline Letters & $14.5(28.6)$ & 5.4 & 23.6 \\
Digits & $31.8(33.2)$ & 21.2 & 42.4 \\
\hline
\end{tabular}

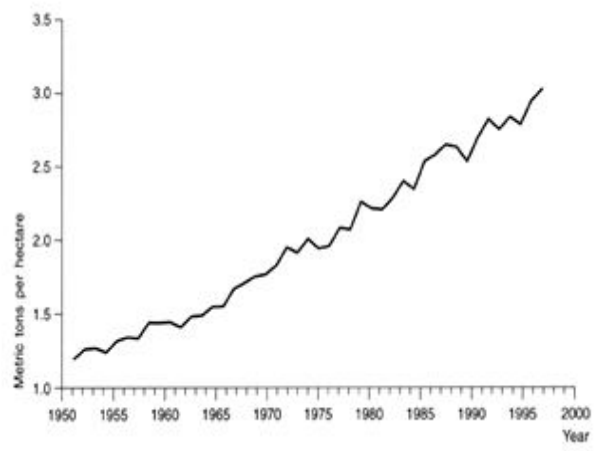

Gambar 1. Nama gambar (contoh gambar 1)

\section{SIMPULAN}

Berisi temuan penelitian yang berupa jawaban atas pertanyaan penelitian atau berupa intisari hasil pembahasan, yang disajikan dalam bentuk paragraf . Saran dapat disampaikan pada bagian ini [Times New Roman, 12, normal].

\section{DAFTAR PUSTAKA}

Penulisan pustaka hanya yang disitasi hanya dalam naskah ini dan diurutkan secara alfabetis dan kronologis.

\section{Buku:}

Gardner, H. 1993. Multiple Intelligences. New York: BasicBooks. 


\section{Buku kumpulan artikel:}

Wahyono, P dan Sugiarti (Eds.). 2013. Pencerahan Pendidikan Masa Depan. Malang: UMM Press

\section{Artikel dalam buku kumpulan artikel:}

Bezooijen, R. V. 2002. Aesthetic evaluation of Dutch: Comparison across dialects, accents and languages. Dalam D. Long, \& D. R. Preston (Eds.), Handbook of perceptual dialectology (Vol. 2, hlm. 13-30). Amsterdam and Philadelphia: Benjamins.

Artikel dalam jurnal atau majalah:

Jaber, M., \& Hussein, R. 2011. Native speakers' perception of non-native English speech. English Language Teaching, 4(4), 77-87.

\section{Dokumen resmi:}

Undang-undang Republik Indonesia Nomor 2 tentang Sistem Pendidikan Nasional. 2003. Surabaya: Usaha Nasional 



\section{FORMULIR BERLANGGANAN JINoP (JURNAL INOVASI PEMBELAJARAN)}

Mohon dicatat sebagai pelanggan JINoP ( Jurnal Inovasi Pembelajaran)

Nama :

Status Pelanggan $\quad$ : lembaga/perorangan* (coret yang tidak sesuai)

Alamat

Kode Pos Telepon

Sejumlah

: Eksemplar, setiap kali terbit, Mulai Volume Tahun

Biaya sebesar Rp. Nomor. irim telah dikirimkan melalui rekening a/n Ibu Sugiarti. Dengan nomor rekening 0388448086 BNI Kantor Cabang Malang

*) Harga langganan : (a) Lembaga Rp 125.000,00 dan

(b) Perorangan Rp 100.000,00 per eksemplar

**) Ongkos kirim : a) Wilayah Jawa Rp 50.000,00;

b) Wilayah Luar Jawa Rp 100.000,00

Pelanggan

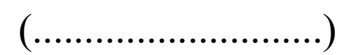


